\title{
Papers
}

\section{Prescribed exercise in people with fibromyalgia: parallel group randomised controlled trial}

\author{
Selwyn C M Richards, David L Scott
}

\begin{abstract}
Objectives To evaluate cardiovascular fitness exercise in people with fibromyalgia.

Design Randomised controlled trial.

Setting Hospital rheumatology outpatients. Group based classes took place at a "healthy living centre." Participants 132 patients with fibromyalgia. Interventions Prescribed graded aerobic exercise (active treatment) and relaxation and flexibility (control treatment).

Main outcome measures Participants' self assessment of improvement, tender point count, impact of condition measured by fibromyalgia impact questionnaire, and short form McGill pain questionnaire.

Results Compared with relaxation exercise led to significantly more participants rating themselves as much or very much better at three months: 24/69 $(35 \%)$ v 12/67 (18\%), $\mathrm{P}=0.03$. Benefits were maintained or improved at one year follow up when fewer participants in the exercise group fulfilled the criteria for fibromyalgia (31/69 v 44/67, $\mathrm{P}=0.01)$. People in the exercise group also had greater reductions in tender point counts $(4.2 v 2.0, \mathrm{P}=0.02)$ and in scores on the fibromyalgia impact questionnaire $(4.0 v 0.6, \mathrm{P}=0.07)$.

Conclusions Prescribed graded aerobic exercise is a simple, cheap, effective, and potentially widely available treatment for fibromyalgia.
\end{abstract}

\section{Introduction}

Medically unexplained symptoms, especially pain, are common reasons for patients consulting their general practitioner and attending hospital clinics. They have major negative impacts on quality of life. Chronic widespread musculoskeletal pain is a particular problem with a community prevalence of $11-13 \%$ in the United Kingdom. ${ }^{1}{ }^{2}$ Fibromyalgia, the severe end of the spectrum, comprises chronic musculoskeletal pain in association with multiple tender points. Its community prevalence is $1 \%{ }^{3}$ Fibromyalgia overlaps with chronic fatigue and other medically unexplained syndromes. ${ }^{4}$

Conventional medical treatment of fibromyalgia with analgesics, non-steroidal anti-inflammatory drugs, and antidepressants is relatively ineffective. Prospective observational studies show little improvement over four to seven years. ${ }^{5-7}$ Exercise therapy is an alternative approach. Its use reflects the cognitive behaviour model of fibromyalgia in which maladaptive fear of worsening symptoms prevents individuals from being active. $^{8-11}$

Several randomised controlled trials of exercise therapy in fibromyalgia have given generally positive results. However they were underpowered, excluded many cases, and lack generalisability because the interventions took place in hospitals and were supervised by highly experienced healthcare professionals. ${ }^{12-18}$ We report a randomised controlled trial that evaluated the prescription of a community based exercise programme in patients with fibromyalgia who were seen in a hospital outpatient rheumatology clinic. Our trial was designed to be inclusive of all cases, widely generalisable, and adequately powered.

\section{Methods}

\section{Participants}

We included in the study men and women aged 18-70 years who had fibromyalgia according to the criteria of the American College of Rheumatology $1990^{19}$ and were able to give informed consent.

We identified potential participants by hand searching copies of all letters sent from clinics to general practitioners to identify patients diagnosed with fibromyalgia who were attending rheumatology clinics at one teaching hospital between January 1997 and June 1998.

We excluded 29 people in whom an alternative medical diagnosis could explain current symptoms and 22 who were unable to attend classes (10 lived too far away, four were too busy, four were too incapacitated, four had other reasons). Other exclusion criteria were severe pulmonary, cardiovascular, renal, or neurological disease precluding involvement in aerobic exercise and inability to cooperate, but no participants were excluded for these reasons.

\section{Trial interventions}

The observer blind parallel group randomised controlled trial evaluated 12 weeks of exercise in 136 participants followed for one year from entry. Participants answered questionnaires and underwent examination before treatment, immediately after treatment (at three months), and at six and 12 months. Participants completed questionnaires before assessment
Poole Hospital
NHS Trust, Poole,
Dorset BH15 2JB
Selwyn C M
Richards
consultant
rheumatologist
King's College
Hospital, London
SE22 8PT
David L Scott
professor of clinical
rheumatology
Correspondence to:
S C M Richards
srichards@poole-tr.
swest.nhs.uk
bmj.com 2002;325:185 
by a single blinded assessor (SR) who recorded physical outcome measures and remained unaware of the allocation throughout the trial. The local research ethics committee approved the study, and all participants gave informed consent.

Participants were randomly assigned in equal proportion to either graded aerobic exercise or relaxation. An independent researcher not involved in the assessments used a random number table for allocation.

Both groups met in hour long classes of up to 18 individuals twice weekly for 12 weeks. Participants continued their medication at entry. They received standardised advice including an explanation of fibromyalgia and encouragement and were told that the exercise offered through prescription would improve their condition. Each week at the classes all individuals received an information leaflet covering an aspect of their condition. The interventions were carried out by personal trainers blinded to the hypothesis of the trial.

Exercise therapy comprised an individualised aerobic exercise programme, mostly walking on treadmills and cycling on exercise bicycles. Each individual was encouraged to increase the amount of exercise steadily as tolerated. When people first started classes they usually did two periods of exercise per class lasting six minutes. By 12 weeks they were doing two periods of 25 minutes at an intensity that made them sweat slightly while being able to talk comfortably in complete sentences.

Relaxation and flexibility comprised upper and lower limb stretches and relaxation techniques based on the published regimen by Ost. ${ }^{20}$ As the classes continued more techniques were introduced progressing through progressive muscle relaxation, release only relaxation and visualisation, cue controlled relaxation, and differential relaxation. This occupied the whole one hour class.

\section{Primary outcome measure}

Our primary outcome measure was the change in self rated global impression, which is a validated measure of overall change from study onset ${ }^{21}$ previously used in exercise intervention trials in fibromyalgia and chronic fatigue syndrome. ${ }^{22-24}$ We measured change on a 7 point scale ranging from 1 (very much worse) to 7 (very much better). We regarded participants with scores of 6 and 7 as responders and those with other scores or who did not attend classes as nonresponders.

Table 1 Details of randomised patients

\begin{tabular}{lcc} 
& Relaxation $(\mathbf{n}=\mathbf{6 7})$ & Exercise $(\mathbf{n}=\mathbf{6 9})$ \\
\hline Median (interquartile range) age (years) & $45(38-52)$ & $48(38-56)$ \\
\hline Median (interquartile range) duration (years) & $4(3-9)$ & $6.5(3-10)$ \\
\hline Median (interquartile range) education (years) & $11(10-14)$ & $12(10-14)$ \\
\hline Single & 33 & 35 \\
\hline Women & 64 & 62 \\
\hline Currently employed & 14 & 23 \\
\hline Receiving social security benefits & 49 & 40 \\
\hline Taking analgesics & 27 & 27 \\
\hline Taking antidepressants & 20 & 47 \\
\hline Fulfil criteria for chronic fatigue syndrome & 48 & $-3.6(1.3)$ \\
\hline Mean (SD) SF-36 summary z scores ${ }^{*}:$ & $-3.9(1.6)$ & $-3.7(0.9)$ \\
\hline Mental component & $-3.9(1.1)$ & \\
\hline Physical component & &
\end{tabular}

page 2 of 4

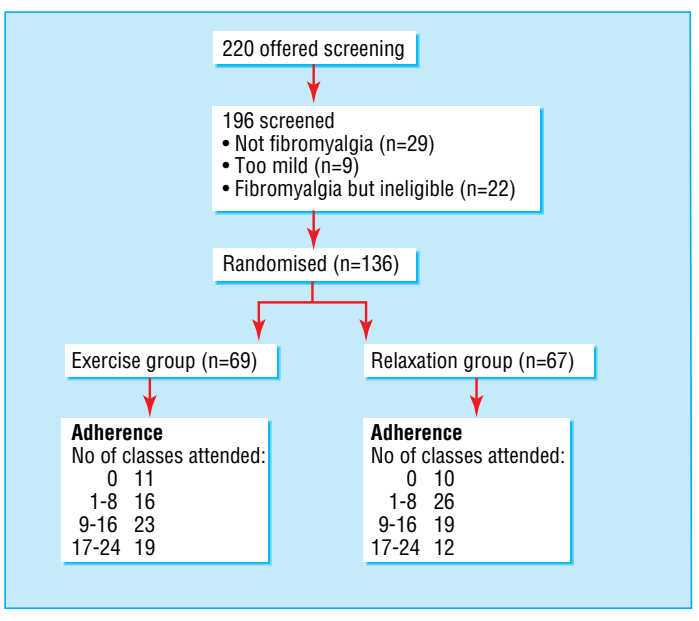

Outline of flow of patients in study

\section{Secondary outcome measures}

To give a tender point count a blinded observer recorded tenderness at the 18 sites specified in the fibromyalgia classification criteria. We used the fibromyalgia impact questionnaire to assesses symptoms, disability, and handicap. ${ }^{25}$ We also used the Chalder fatigue scale to assess physical and mental fatigue in two different constructs, ${ }^{26}$ the short form McGill pain questionnaire, ${ }^{27}$ and SF-36. ${ }^{28}$

\section{Sample size and analysis}

The study was powered to detect a $25 \%$ difference between the two arms (that is, response rates of $20 \%$ in the control arm and 45\% in the active treatment arm) when treatment was completed at three months with a significance level of 5\% and $80 \%$ power. This needed 51 participants in each arm. With allowance for a 30\% dropout rate we calculated we would need a final sample size of 132 (66 per arm).

We used Fisher's exact test for comparisons at three months. We classified participants who failed to attend any classes as non-responders and analysed data on an intention to treat basis. We replaced any missing follow up data with the last know value even if this was the baseline value. We used non-parametric methods as data were not normally distributed. We used MannWhitney U tests for analyses between groups and Wilcoxon signed rank tests for changes from baseline within groups.

\section{Results}

The figure summarises the participants identified, contacted, and enrolled into the trial. We randomised 136 participants, and 108 attended for baseline assessments and at least one class. Table 1 shows baseline assessments of the two groups. The participants were highly disabled (mean summary SF-36 scores $>3$ SD below normal), and $89(65 \%)$ were receiving benefits. The two groups were comparable for all recorded demographic characteristics. Only 72 (53\%) participants attended over one third of the classes.

\section{Intention to treat analysis of the primary outcome} At three months 24/69 (35\%) participants randomised to the exercise arm were much better or very much better compared with $12 / 67(18 \%)$ randomised to the 
Table 2 Tender point counts in people with fibromyalgia over time according to allocation to exercise or relaxation classes

\begin{tabular}{|c|c|c|c|c|}
\hline \multirow[b]{2}{*}{ Time } & \multicolumn{2}{|c|}{ Mean scores $(95 \% \mathrm{CI})$} & \multirow{2}{*}{$\begin{array}{l}\text { Mean change between groups } \\
\qquad(95 \% \mathrm{Cl})\end{array}$} & \multirow[b]{2}{*}{$P$ value } \\
\hline & Relaxation group ( $n=67$ ) & Exercise group $(n=69)$ & & \\
\hline Baseline & $14.0(13.4$ to 14.6$)$ & 14.4 (13.7 to 15.1) & NA & NA \\
\hline 3 months & 11.8 (10.9 to 2.8$)$ & $10.6(9.2$ to 12.0$)$ & $1.1(-0.47$ to 2.6$)$ & 0.21 \\
\hline 6 months & 11.2 (10.0 to 12.3$)$ & 10.2 (8.9 to 11.5$)$ & $1.4(-0.1$ to 2.8$)$ & 0.07 \\
\hline 1 year & $12.0(10.8$ to 13.0$)$ & 10.2 (8.8 to 11.6$)$ & 2.2 (0.63 to 3.7$)$ & 0.019 \\
\hline
\end{tabular}

NA=not applicable.

${ }^{*}$ Comparison of changes from baseline between arms by Wilcoxon signed ranks test.

Table 3 Scores on fibromyalgia impact questionnaire scores in people with fibromyalgia over time according to allocation to exercise or relaxation classes

\begin{tabular}{|c|c|c|c|c|}
\hline \multirow[b]{2}{*}{ Time } & \multicolumn{2}{|c|}{ Mean scores $(95 \% \mathrm{Cl})$} & \multirow{2}{*}{$\begin{array}{l}\text { Mean change between groups } \\
\qquad(95 \% \mathrm{Cl})\end{array}$} & \multirow[b]{2}{*}{$P$ value } \\
\hline & Relaxation group ( $n=65$ ) & Exercise group ( $n=68$ ) & & \\
\hline Baseline & 56.6 (53.6 to 59.5$)$ & 59.6 (56.6 to 62.5$)$ & NA & NA \\
\hline 3 months & 54.7 (51.1 to 58.3 ) & 55.0 (51.7 to 59.1$)$ & $1.9(-2.5$ to 6.3$)$ & 0.5 \\
\hline 6 months & 56.4 (53.0 to 59.8$)$ & 54.2 (51.1 to 58.4) & $4.4(-0.3$ to 9.0$)$ & 0.05 \\
\hline 1 year & 56.0 (52.8 to 59.5$)$ & 55.6 (52.4 to 59.9) & $2.5(-2.7$ to 7.8$)$ & 0.07 \\
\hline
\end{tabular}

$\mathrm{NA}=$ not applicable.

relaxation arm (Fisher's test $\mathrm{P}=0.032$ for difference). Twelve participants in each group had dropped out by three months, and these were all rated as nonresponders. The benefits were maintained at 12 months in $26(38 \%)$ and $15(22 \%)$ participants respectively $(\mathrm{P}=0.06)$.

Tender point count and criteria for fibromyalgia In both groups the tender point counts had fallen significantly at three months (table 2 ). This reduction persisted for 12 months $(\mathrm{P}<0.001$, Wilcoxon signed ranks test), though by then the difference between the two groups was greater and favoured the exercise group ( $\mathrm{P}=0.02$ on Mann-Whitney $\mathrm{U}$ test). This fall in tender point counts meant that at 12 months only $75(55 \%)$ of participants still met the diagnostic criteria for fibromyalgia, and significantly fewer of them were in the exercise group (31 $v 44$ in relaxation group, $\mathrm{P}=0.017$ by Fisher's exact test).

\section{Secondary outcome measures}

At three months there were no significant changes between the two groups in the results from the fibromyalgia impact questionnaire. However improvement was greater in the exercise arm, and this benefit increased with follow up (table 3). The physical, mental, and total fatigue scores as measured by the Chalder fatigue scale all showed significant falls (between $20-30 \%$ of baseline values) in both groups at three months, and this was maintained at 12 months (data not shown). There were no significant differences between groups. The McGill pain scores had fallen significantly at three months in both groups $(14 \%$ of baseline values with exercise and $6 \%$ with relaxation), and this was maintained in the exercise arm at six months (10\% of baseline values). There were no significant differences between groups (data not shown). From the SF-36 the physical components summary scores improved in both groups at three months. The mean (SD) scores at baseline were -3.6 (1.3) in the exercise group and -3.3 (1.6) in the relaxation group. There were no significant differences between groups. The mental components summary scores were virtually unchanged.

We did not record any adverse events in either group.

\section{Discussion}

Our results show that a three month programme of prescribed graded aerobic fitness exercises significantly benefits participants' global self rating of fibromyalgia. Tender point counts and scores on fibromyalgia impact questionnaires also improved. Some benefits, like the fall in tender point counts, lasted 12 months.

Previous reports have described exercise interventions performed by highly qualified healthcare professionals in selected hospital patients. We excluded only a few people from our pragmatic trial, despite studying severely affected people whose pain and fatigue had lasted several years. Our instructors were personal trainers with no special experience in providing exercise for people with ill health. Our patients attended classes of their own accord and arranged their own transport, and the large class sizes minimised costs. Though people in the relaxation arm attended fewer classes, this may have been due to a lack of perceived benefits.

This study utilised facilities at a "healthy living centre." These centres are funded through the new opportunities fund of the National Lottery with a UK budget of $£ 300 \mathrm{~m}(\$ 460 \mathrm{~m}, € 470 \mathrm{~m})^{29}$ and aim to promote health by helping people of all ages to maximise their health and wellbeing. Their health benefits have not previously been evaluated, and our study is the first published trial that shows they are effective.

A systematic review of Medline and a paper search of cited articles identified nine previous trials of exercise therapy in people with fibromyalgia. Each trial had 35-149 participants, making a total of 727. All reported positive findings with benefits lasting six months or longer in some trials. ${ }^{18}$ Two trials had negative results, ${ }^{13}{ }^{14}$ and three had inadequate control groups. $^{30-32}$ Three studies with global self rating outcome measures reported improvements in 51 $(68 \%)$ participants (28-85\% between studies). ${ }^{16}{ }^{22}{ }^{30}$ Our study design addressed the weakness of previous trials by being adequately powered, involving an appropriate control group, and including one year follow up.

Fibromyalgia is a common presentation in rheumatology clinics. The 136 patients we studied were selected from 7806 (2021 new) rheumatology clinic 


\section{What is already known on this topic}

Fibromyalgia is common debilitating medically unexplained condition affecting around $1 \%$ of the population

Current treatments are unsatisfactory and most people remain the same after several years of treatment

Exercise as a treatment given by healthcare professionals in highly specialised centres is of some short term benefit

\section{What this study adds}

For people with fibromyalgia prescribed graded aerobic exercise is an effective treatment that leads to improvements in self reported health status

Prescribed exercise can be undertaken effectively in the community by personal trainers previously inexperienced in management of people with ill health

attendances in 1997. Their low SF-36 scores indicate high levels of disability, most were unemployed and receiving benefits, and many came from ethnic minorities. Our results indicate that such severely affected individuals benefit from a simple community based exercise intervention programme readily available through prescription.

Exercise treatment has limitations. Compliance is a considerable problem, giving high dropout rates. Reasons include the initial increases in pain and stiffness immediately after exercise and patients believing that exercise worsens the condition. Future strategies to increase the efficacy of exercise as an intervention should confront the issue of compliance. Potential strategies include additional cognitive behavioural therapy and providing physiological explanations for symptoms. ${ }^{33} 34$

Contributors: SCMR designed and performed the study; DLS advised and supervised. Advice on planning the study was received from the department of psychological medicine at King's College Hospital, especially Dr Alicia Deale. Interventions were performed by personal trainers employed by Holmes Place plc. Statistical advice was given by Dr Peter Thomas, Dorset Research and Development Support Unit, and Drs Richard Hooper and Nora Donaldson, King's College Hospital, London. SCMR and DLS are guarantors.

Funding: This study was funded by a research training fellowship of the London region of the NHS executive.

Competing interests: None declared.

1 Macfarlane GJ, Morris S, Hunt IM, Benjamin S, McBeth J, Papageorgiou AC, et al. Chronic widespread pain in the community: the influence of psychological symptoms and mental disorder on healthcare seeking psychological symptoms and mental
behavior. J Rheumatol 1999:26:413-9.

2 Croft P, Rigby AS, Boswell R, Schollum J, Silman A. The prevalence of chronic widespread pain in the general population. $J$ Rheumatol 1993;20:710-3.
3 Lawrence RC, Helmick CG, Arnett FC, Deyo RA, Felson DT, Giannini $\mathrm{EH}$, et al. Estimates of the prevalence of arthritis and selected musculoskeletal disorders in the United States. Arthritis Rheum 1998;41:778-99.

4 White KP, Speechley M, Harth M, Ostbye T. Co-existence of chronic fatigue syndrome with fibromvalgia syndrome in the general population. A controlled study. Scand J Rheumatol 2000;29:44-51.

5 Wolfe F, Anderson J, Harkness D, Bennett RM, Caro XJ, Goldenberg DL, et al. Health status and disease severity in fibromyalgia: results of a six-center longitudinal study. Arthritis Rheum 1997;40:1571-9.

6 Wigers SH. Fibromyalgia outcome: the predictive values of symptom duration, physical activity, disability pension, and critical life events-a 4.5 year prospective study. J Psychosom Res 1996;41:235-43.

7 Ledingham J, Doherty S, Doherty M. Primary fibromyalgia syndrome-an outcome study. Br J Rheumatol 1993;32:139-42.

8 Lethem J, Slade PD, Troup JD, Bentley G. Outline of a fear-avoidance model of exaggerated pain perception-I. Behav Res Ther 1983;21:401-8.

9 Slade PD, Troup JD, Lethem J, Bentley G. The fear-avoidance model of exaggerated pain perception-II. Behav Res Ther 1983;21:409-16.

10 Philips HC. Avoidance behaviour and its role in sustaining chronic pain. Behav Res Ther 1987;25:273-9.

11 Surawy C, Hackmann A, Hawton K, Sharpe M. Chronic fatigue syndrome: a cognitive approach. Behav Res Ther 1995;33:535-44.

12 McCain GA. Role of physical fitness training in the fibrositis/fibromyalgia syndrome. Am J Med 1986;81:73-7.

13 Mengshoel AM, Komnaes HB, Forre O. The effects of 20 weeks of physical fitness training in female patients with fibromyalgia. Clin Exp Rheumatol 1992;10:345-9.

14 Burckhardt CS, Mannerkorpi K, Hedenberg L, Bjelle A. A randomized, controlled clinical trial of education and physical training for women with fibromyalgia.J Rheumatol 1994;21:714-20.

15 Martin L, Nutting A, MacIntosh BR, Edworthy SM, Butterwick D, Cook J An exercise program in the treatment of fibromyalgia. I Rheumatol 1996;23:1050-3.

16 Wigers SH, Stiles TC, Vogel PA. Effects of aerobic exercise versus stress management treatment in fibromyalgia. A 4.5 year prospective study. Scand J Rheumatol 1996;25:77-86.

17 Buckelew SP, Conway R, Parker J, Deuser WE, Read J, Witty TE, et al Biofeedback/relaxation training and exercise interventions for fibromyalgia: a prospective trial. Arthritis Care Res 1998;11:196-209.

18 Gowans SE, deHueck A, Voss S, Richardson M. A randomized, controlled trial of exercise and education for individuals with fibromyalgia. Arthritis Care Res 1999:12:120-8.

19 Wolfe F, Smythe HA, Yunus MB, Bennett RM, Bombardier C, Goldenberg DL, et al. The American College of Rheumatology 1990 criteria for the classification of fibromyalgia. Report of the multicenter criteria committee. Arthritis Rheum 1990;33:160-72.

20 Ost L. Applied relaxation: description of a coping technique and review of controlled studies. Behav Res Ther 1987;25:397-409.

21 Guy W, ed. ECDEU assessment manual for psychopharmacology. Rockville MD: US National Institute of Health, 976:218-22.

22 McCain GA, Bell DA, Mai FM, Halliday PD. A controlled study of the effects of a supervised cardiovascular fitness training program on the manifestations of primary fibromyalgia. Arthritis Rheum 1988;31:1135 41.

23 Fulcher KY, White PD. Randomised controlled trial of graded exercise in patients with the chronic fatigue syndrome. $B M J$ 1997;314:1647-52.

24 Keel PJ, Bodoky C, Gerhard U, Muller W. Comparison of integrated group therapy and group relaxation training for fibromyalgia. Clin J Pain $1998 \cdot 14 \cdot 232-8$.

25 Burckhardt CS, Clark SR, Bennett RM. The fibromyalgia impact questionnaire: development and validation. J Rheumatol 1991;18:728-33.

26 Chalder T, Berelowitz G, Pawlikowska T, Watts L, Wessely S, Wright D, et al. Development of a fatigue scale. J Psychosom Res 1993;37:147-53.

27 Melzack R. The short-form McGill pain questionnaire. Pain 1987;30:191-7.

28 Garratt AM, Ruta DA, Abdalla MI, Buckingham JK, Russell IT. The SF-36 health survey questionnaire: an outcome measure suitable for routine use within the NHS? BMJ 1993;306:1440-4.

29 Department of Health. Healthy living centres. London: Department of Health, 1997 (MISC (97)83)

30 Verstappen FTJ vS-HH, Bolwijn PH, van der Linden S, Kuipers H. Effect of a group activity program for fibromyalgia patients on physical fitness and well being. I Musculoskeletal Pain 1997:5:17-28.

31 Gowans SE, deHueck A, Voss S, Richardson M. A Randomized, controlled trial of exercise and education for individuals with fibromyalgia Arthritis Care Res 1999;12:120-8.

32 Bailey A, Starr L, Alderson M, Moreland J. A comparative evaluation of a fibromyalgia rehabilitation program. Arthritis Care Res 1999;12:336-40.

33 Powell P, Bentall RP, Nye FJ, Edwards HT. Randomised controlled trial of patient education to encourage graded exercise in chronic fatigue syndrome. BMJ 2001;322:1-5.

34 White KP, Nielson WR. Cognitive behavioral treatment of fibromyalgia syndrome: a followup assessment. J Rheumatol 1995;22:717-21.

(Accepted 25 February 2002) 